\title{
Associative strength and degree of competition in verbal paired-associate learning'
}

\author{
Alfred Castaneda, QUEENS COLLEGE AND INSTITUTE FOR CHILD DEVELOPMENT AND EXPERIMENTAL EDUCATION, \\ Richard D. Ddom, VANDERBILT UNIVERSITY \\ THE CITY UNIERSITY OF NEW YORK
}

\begin{abstract}
Abstraet
The present study dealt with paired-associate learning in elementary school age children as a function of associative strength and degree of competition. Two conditions were compared, each involving S-R pairs mediated by weak as well as strong associative strengths. The pairs mediated by strong associative strengths were identical in both conditions. In Condition I the S-R pairs mediated by weak associative strengths were constructed so as to maximize generalization of their response items to the stimulus items for the strongly associated S-R pairs. Performance on these latter S-R pairs in Condition I was found to be significantly poorer in comparison to identical S-R items in Condition II which minimized the presence of competing associations.
\end{abstract}

\section{Introduction}

A within-list method for varying the factors of associative strength and degree of competition in pairedassociate learning has been recently proposed by Spence (1956). This method involves constructing the pairedassociate list such that the presence of competing associations is maximized for a portion of the pairedassociate items comprising the list but minimized for the remaining portion. The basic feature of this condition (I) is diagrammed below in conjunction with the condition (II) with which it is compared in the present study:
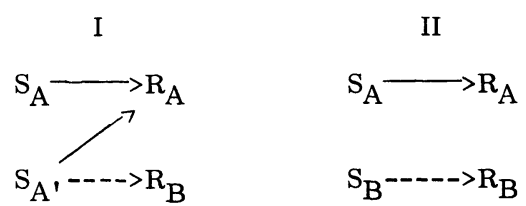

The strong initial associative connection depicted by the solid arrows, e. g., $\mathrm{S}_{\mathrm{A}} \longrightarrow \mathrm{R}_{\mathrm{A}}$, implies that performance would be better relative to the S-R items mediated by initially weak associative connections, i. e., $\mathrm{S}_{\mathrm{A}}{ }^{\prime-\cdots>\mathrm{R}_{\mathrm{B}}}, \mathrm{S}_{\mathrm{B}} \cdots-\cdots \mathrm{R}_{\mathrm{B}}$. However, assuming a basis for the development of generalized tendencies between the stimulus items $\left(\mathrm{S}_{\mathrm{A}}, \mathrm{S}_{\mathrm{A}}\right)$ in Condition I, learning the S-R items mediated by the weaker associative strength $\left(\mathrm{S}_{\mathrm{A}},-\cdots>\mathrm{R}_{\mathrm{B}}\right)$ would be expected to be impaired relative

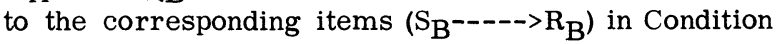
II due to the interference generated by the initially strong tendency for the stimulus item $S_{A}$, to evoke $R_{A}$. Central to the present study, however, is the hypothesis that as the association between $S_{A}$, and $R_{B}$, though initially weak, is strengthened through learning, a generalized association develops between the stimulus item $\left(\mathrm{S}_{\mathrm{A}}\right)$ and the response item $\left(\mathrm{R}_{\mathrm{B}}\right)$ of the to-beassociated $S-R$ pairs mediated by an initially weak associative strength, i. e., $\mathrm{S}_{\mathrm{A}^{\prime}}--->\mathrm{R}_{\mathrm{B}}$. This assumption has been recently invoked (Lovaas, 1960; Ramond, 1953; Spence, Farber, \& McFann, 1956; Spence, Taylor, \& Ketchel, 1956) to account for the consistent finding that a heightened motivational level produced by induced muscular tension or determined by individual differences in anxiety level (Taylor Manifest Anxiety Scale) produce superior performance on the $\mathrm{S}_{A} \longrightarrow \mathrm{R}_{A}$ type items during the early trials but lead to poorer performance in the later trials. Thus, presuming that the stimulus item $\left(S_{B}\right)$ of the initially weak associated S-R pair in Condition II is selected so as to minimize generalization to the stimulus item $\mathrm{S}_{\mathrm{A}}$, learning the association $\mathrm{S}_{\mathrm{A}} \longrightarrow \mathrm{R}_{\mathrm{A}}$ would be expected to be better in comparison to the correspondingly identical $S-R$ item in Condition I even though its associative strength is equally and initially high in both conditions.

\footnotetext{
Subjects

The Ss were 72 fourth, fifth, and sixth grade boys and girls. Twentyfour Ss were selected from each grade level and randomly assigned to the two basic conditions.

Ipparatus and Verbal Material

A Hunter Card Master (Model 340) was used to present the verbal material which consisted of adjectives typed in uppercase letters. The adjectives were selected from a word list standardized on a population of fourth, fifth, and sixth graders and which is described elsewhere (Castaneda, Fahel, \& Odom, 1960). The associative strength between a given stimulus word and response word is defined by the percentage of these standardization $\mathrm{Ss}$ who gave the same response word as an association during an 8-sec. interval.

The S-R items were constructed in accord with the diagram outlined above and are presented in Table 1 along with their association values separately for each of the two conditions. Three sets of word pairs were employed for each condition, each set having one highand one low-association word pair. A set consists of an asterisked pair and the pair immediately below it. The sets were constructed so that both conditions had the same stimulus words for the highassociation pairs, and the same response words were used for all pairs.
}

Table 1. Competitive and Noncompetitive Word Pairs and Their Association Value

Stimuli

Response

Condition I Condition II

$\begin{array}{lcl}\text { *Beautiful } & \text { *Beautiful } & \text { Ugly (24) } \\ \text { Pretty (24) } & \text { Poor } & \text { Less (1) } \\ \text { *Warm } & \text { *Warm } & \text { Cold (35) } \\ \text { Hot (32) } & \text { Hurt } & \text { Fast (1) } \\ \text { *Little } & \text { *Little } & \text { Big (34) } \\ \text { Small (23) } & \text { Still } & \text { More (1) }\end{array}$

*High association-value pairs. 
Association values (given in parentheses) are expressed in percentages for each S-R pair, e.g., beautiful-ugly (24). The percentages indicated after each stimulus word of the low-association pairs in Condition I represent the association value between that stimulus word and the response word of the high-association pair in its set, e. g., hot (32) - cold. For each set in Condition II the association value between the stimulus word of the low-association pair and the response word of the high-association pair was initially low (1\% or less). The association values between words across the separate sets were also low $(1 \%$ or less in each condition.

\section{Procedure}

Part of the instructions to all Ss describing the method of learning required $\mathrm{S}$ to read an alphabetized list of 24 words which included the 12 words to appear in the experimental lists. This list was incorporated in the procedure as a precautionary measure to identify those Ss unable to read the words appearing in the experimental list. The additional 12 words in this list were inserted in an attempt to prevent $S$ from attending too greatly to the words which were to eventually appear in the paired-associate task. If $\mathrm{S}$ failed to read correctly one or more of the words to be used in the pairedassociate list, he was prompted and upon completion the entire list was reread. The criterion for rejecting an $\mathrm{S}$ was failure to read one or more of the paired-associate words during the second reading; however, none of the Ss were rejected on this basis.

Each stimulus word was exposed for a 6-sec. period composed of a 3-sec. anticipation interval and a 3-sec. simultaneous presentation with the response word. The inter-pair interval was 2-sec. and a 10-sec. interval followed each trial (one presentation of all the word pairs). The criterion for learning was one errorless trial or a maximum of 15 trials. Correct responses, errors of omission and overt errors were recorded on each trial.

\section{Results}

Learning curves in terms of mean percentage of correct anticipations plotted separately for the highand-low-association pairs within each condition are presented in Fig. 1.

As may be seen, the curves representing performance on the high-association pairs are higher in comparison to the low-association pairs in both conditions. With the exception of trial 1, the curves for Condition II are higher than those of Condition I on the high-association pairs as well as in the case of the low-association pairs. Indeed, it may be noted that the performance on the low-association pairs in Condition II is better than the performance of Ss in Condition I on the highassociation pairs on Trials 12-15.

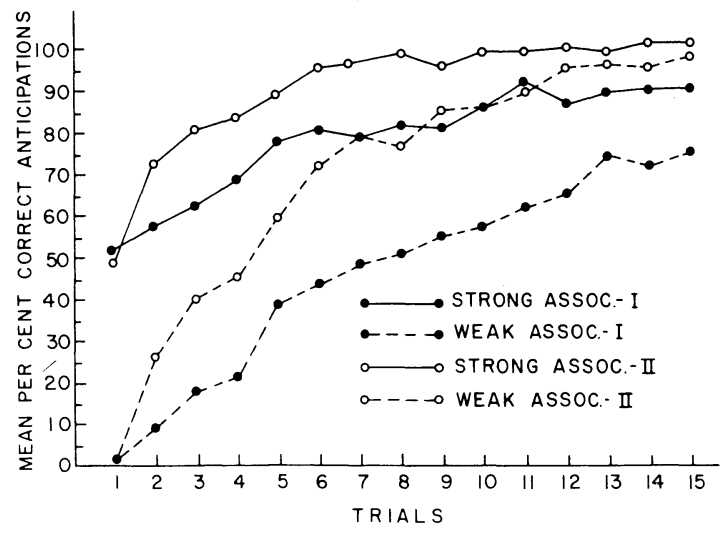

Fig. 1. Per cent correct anticipations as a function of associative strength and competition.
For the analysis of variance the data presented in Fig. 1 were grouped in blocks of five. The analysis revealed the following effects to be significant: Conditions $(\mathrm{F}=31.09 ; \mathrm{df}=1 / 66 ; \mathrm{p}<.001)$, Association Value $(F=351.12 ; \mathrm{df}=1 / 66 ; \mathrm{p}<.001)$, Trials $(\mathrm{F}=286.58$; $\mathrm{df}=2 / 132 ; \mathrm{p}<.001)$, Association Value $\mathrm{x}$ Conditions $(\mathrm{F}=16.40 ; \mathrm{df}=1 / 66 ; \mathrm{p}<.001)$, Association Value $\mathrm{x}$ Trials $(\mathrm{F}=38.59 ; \mathrm{df}=2 / 132 ; \mathrm{p}<.001)$, and Condition $\mathrm{x}$ Trials $(F=4.33 ; \mathrm{df}=2 / 132 ; \mathrm{p}<.05)$. A $t$ test based on the percentage of correct anticipations on Trials 2-15 comparing Condition I and II on the high-association pairs was found to be significant at the .001 level $(t=4.69$; $\mathrm{df}=70$ ).

\section{Diseussion}

The finding that performance in Condition II was superior to performance in Condition I on those S-R pairs mediated by an initially high associative strength is consistent with the hypothesis described earlier and which was originally proposed by Ramond (1953) in connection with verbal paired-associate learning.

From a general methodological standpoint the implication of the findings of the present study seems clear. That is, while the within-list or within-S method of varying such factors as associative strength and associative interference may be economical and efficient from the viewpoint of experimental design, other considerations may suggest that the possible interactive effects of thses factors, if varied by the within-list method, may be psychologically complicated. If such interactive effects are not anticipated either on the basis of fact or theory, the within-list method may serve to confound rather than clarify those theoretical issues it is designed to assess. The initial efforts of Twedt \& Underwood (1959) in examining differences produced between within- versus between-list variations in paired-associate learning represents the type of attention to this problem that is needed.

\section{References}

CASTANEDA, A., FAHEL, L. S., \& ODOM, R. Associative characteristics of sixty-two adjectives and their relation to verbal paired-associate learning in children. Child Developm., 1961, 32, 297-304.

LOVAAS, O. I. Supplementary report: The relationship of induced muscular tension to manifest anxiety in learning. J.exp. Psychol., 1960, 59, 205-206.

RAMOND, C. K. Anxiety and task determiners of verbal performance. J.exp. Psychol., 1953, 46, 120-124.

SPENCE, K. W. Behavior theory and conditioning. New Haven: Yale Univer. Press, 1956.

SPENCE, K. W., FARBER, I. E., \& McFANN, H. H. The relation of anxiety (drive) level to performance in competitional and noncompetitional paired-associates learning. J. exp. Psychol., 1956, 52, 296-305.

SPENCE, K. W., TAYLOR, J., \& KETCHEL, R. Anxiety (drive) level and degree of competition in paired-associates learning. J.exp. Psychol., 1956, 52, 306-310.

TWEDT, H. M., \& UNDERWOOD, B. J. Mixed vs. unmixed lists in transfer studies. J. exp. Psychol., 1959, 58, 111-116.

\section{Note}

1. The present study was supported by a National Institute of Mental Health grant (No. M4240) to the first author. 